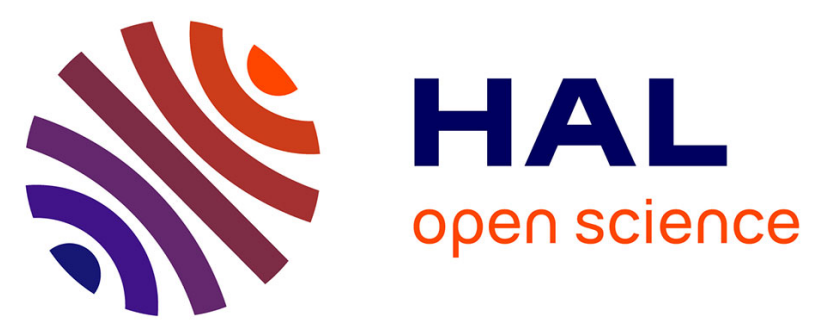

\title{
Dynamic simulation and control of solar biomass gasification for hydrogen-rich syngas production during allothermal and hybrid solar/autothermal operation
}

Houssame Boujjat, Giberto Mitsuyoshi Yuki Junior, Sylvain Rodat, Stéphane

Abanades

\section{To cite this version:}

Houssame Boujjat, Giberto Mitsuyoshi Yuki Junior, Sylvain Rodat, Stéphane Abanades. Dynamic simulation and control of solar biomass gasification for hydrogen-rich syngas production during allothermal and hybrid solar/autothermal operation. International Journal of Hydrogen Energy, 2020, 45 (48), pp.25827-25837. 10.1016/j.ijhydene.2020.01.072 . hal-02566067

\section{HAL Id: hal-02566067 https://hal.science/hal-02566067}

Submitted on 5 Nov 2020

HAL is a multi-disciplinary open access archive for the deposit and dissemination of scientific research documents, whether they are published or not. The documents may come from teaching and research institutions in France or abroad, or from public or private research centers.
L'archive ouverte pluridisciplinaire HAL, est destinée au dépôt et à la diffusion de documents scientifiques de niveau recherche, publiés ou non, émanant des établissements d'enseignement et de recherche français ou étrangers, des laboratoires publics ou privés. 


\title{
Dynamic simulation and control of solar biomass gasification for hydrogen-rich syngas production during allothermal and hybrid solar/autothermal operation
}

\author{
Houssame BOUJJAT ${ }^{1,2}$, Giberto MITSUYOSHI YUKI JUNIOR ${ }^{1}$, Sylvain RODAT $^{3}$, Stéphane ABANADES R $^{3, *}$ \\ ${ }^{1}$ CEA-LITEN Solar and Thermodynamic Systems Laboratory (L2ST), F-38054 Grenoble, France \\ ${ }^{2}$ Univ. Grenoble Alpes, F-38000 Grenoble, France \\ ${ }^{3}$ Processes, Materials and Solar Energy Laboratory, PROMES-CNRS, 7 Rue Du Four Solaire, 66120 Font-Romeu, \\ France \\ *Corresponding author: Stephane.Abanades@ promes.cnrs.fr
}

\begin{abstract}
:
Solar biomass steam gasification using concentrated sunlight offers an efficient means of storing intermittent solar energy into renewable solar fuels while upgrading the carbonaceous feedstock. Such solar-driven (allothermal) processes have demonstrated the ability and the effectiveness for the production of high quality hydrogen-rich syngas, but they suffer from inherent barriers related to the variability of solar energy caused by cloud passages and shut off at night. The concept of hybrid solar/autothermal gasification appears promising to meet the requirement for stable and continuous operation under fluctuating or intermittent solar irradiation. To date, dynamic modelling to simulate coupled solar/combustion heating and steam gasification using real solar irradiation data has never been proposed and could be used to predict the annual performance of large-scale solar gasification plants. In this study, a dynamic mathematical model of a scaled-up solar gasification reactor was developed. The model was composed of a system of differential equations that were derived from unsteady mass and energy conservation equations. After an experimental validation step with the results from a lab-scale solar reactor, the dynamic model was applied at large scale to determine the reactor temperature and syngas production evolution during continuous day and night operation in both solar-only (allothermal) and hybrid solar/autothermal modes. Different reactants feeding management strategies were proposed and compared with the aim of achieving enhanced syngas productivity and optimized use of solar energy during solar-aided steam gasification. It was shown that the hybrid mode with partial oxy-combustion of the feedstock and dynamic feeding control results in the most stable process operation upon fluctuating solar power input, while ensuring continuous production of $\mathrm{H}_{2}$ and $\mathrm{CO}$ at night and during cloudy periods.
\end{abstract}


Keywords: Solar energy, biomass, hybrid gasification reactor, continuous operation strategy, dynamic modelling

\section{Introduction}

Owing to the growing demand of energy in human societies, to the dwindling of fossil fuel reserves and to climate change, the need for a sustainable energy transition is growing stronger. The development of renewable energies thus appears as the keystone of this transition. The use of high temperature solar heat obtained by concentrating direct radiations as an external energy source for thermochemical and energy conversion processes appears as a relevant solution [1]. Steam gasification is one of the most effective and efficient techniques to generate $\mathrm{H}_{2}$ and $\mathrm{CO}$ from biomass [2]. Through a complex mechanism involving hundreds of chemical species and thousands of reactions, biomass gasification aims to produce a synthesis gas (syngas) composed mainly of hydrogen and carbon monoxide. The latter can be used for the generation of second-generation synthetic fuels, chemicals and energy carriers. The ideal stoichiometric gasification reaction considering lignocellulosic biomass (with molecular formula of $\mathrm{C}_{6} \mathrm{H}_{9} \mathrm{O}_{4}$ ) can be written as:

$\mathrm{C}_{6} \mathrm{H}_{9} \mathrm{O}_{4}+2 \mathrm{H}_{2} \mathrm{O} \rightarrow 6 \mathrm{CO}+6.5 \mathrm{H}_{2} \quad \Delta_{\mathrm{r}} \mathrm{H}(298 \mathrm{~K})=0.8 \mathrm{MJ} / \mathrm{mol}$

This reaction is strongly endothermic and thereby requires high temperature $\left(>1000^{\circ} \mathrm{C}\right)$ to reach thermodynamic equilibrium, yielding $\mathrm{H}_{2}$ and $\mathrm{CO}$ as the main gas products. In conventional gasification systems, the enthalpy of the reaction is provided by burning at least $30 \%$ of the feedstock. This penalizes the complete use of the biomass, lowers the syngas yield and quality and leads to the contamination of syngas by combustion by-products. By combining concentrated solar energy and biomass thermochemical gasification, it is possible to take advantage of both resources. Indeed, since high-temperature solar energy is used to supply the required gasification process heat, biomass feedstock is entirely dedicated to produce hydrogen and carbon monoxide (syngas). Accordingly, solar gasification promotes biomass valorization and offers an efficient means of storing intermittent solar energy into renewable solar fuels.

At laboratory scale, several cavity-type solar reactors were previously studied. These reactors are characterized by a large internal surface area and a small aperture to let the solar radiations enter. They were extensively used due to their high absorption efficiency arising from low radiation losses. Packed-beds [3-4] were used for the gasification of a stationary charge that does not need to be entrained or fluidized. This makes them simple to construct and relatively economical. Fluidized beds [5-6] are commonly used technologies for biomass 
gasification. Just as in conventional processes, the temperature reached is between $800^{\circ} \mathrm{C}$ and $900^{\circ} \mathrm{C}$ to prevent bed agglomeration due to ash melting. Entrained flow and vortex flow concepts were also solarized [7]. These reactors transport concurrently a finely ground particle feed along with the gasifying agent. By turbulence, a high mixing rate is achieved and the gasification temperature is generally above $1400^{\circ} \mathrm{C}$. To reach high conversion efficiencies, the injected solid materials should nevertheless react within short residence times. Another type of solar reactors makes use of molten salts as both heat transfer fluid and catalysts for gasification [8]. Molten salts constitute an effective heat transfer medium and provide consistent thermal storage of solar energy. Process heat can this way be supplied directly by the molten salts during periods of low solar irradiance. For large-scale applications, concentrating high-flux solar technologies (e.g., towers [9] or beam-down [10]) can be used as they achieve high concentration ratios (C 1000) [1]. The coupling with additional non-imaging optics such as CPCs (Compound Parabolic Concentrators) may be necessary to allow larger concentration and reach the required high gasification temperatures.

If the ability of such solar processes to produce high quality syngas has been widely proven at laboratory scale, large-scale solar gasification struggles to set up. Indeed, high degree of reliability is required for their industrial implementation. Dynamic modelling to account for unsteady state phenomena comes as a key knowledge tool to assist policy and decision makers, advisers and operators for the design and the study of process technoeconomics. Recent studies have focused on the modelling of solar gasification plants for energy-related purposes such as the generation of liquid fuels, heat, cold and power. In this respect, pseudo-dynamic models that assume steady state at each time step and global thermodynamic approaches were widely used [11-17]. Kaniyal et al. [11] studied the energetic and environmental performance of a Coal-To-Liquid (CTL) process integrated with a solar hybridized oxygen blown gasifier. The dynamic operation of the solar CTL system was modeled using MATLAB code that assumed steady-state operation in each time-step using Aspen Plus and Aspen HYSYS (v7.1). Different gasification temperature scenarios were studied. It was found that under equilibrium conditions at $1400^{\circ} \mathrm{C}$ and 1 bar, the total energetic output is improved by $21 \%$ on annual average with a reduction of $30 \%$ in greenhouse gas emissions as compared to a conventional non-solar process. In the same vein, Sudiro et al. [12] studied simultaneous natural gas reforming and coal gasification. The complete process (including Fischer-Tropsch (FT) synthesis, hydrocracking reactor, and separation of products) from coal and methane to synthetic fuels was simulated using steady state conditions on Aspen Plus. The study showed that the solar process emits much less $\mathrm{CO}_{2}$ than CTL and coupled GTL (Gas-To-Liquid) and CTL processes (0.67 kg/kg fuel). Salemme et al. [13] simulated a solar-aided biomass gasification system for pure hydrogen production with the commercial software Aspen Plus. The system variables were the biomass moisture and the amount of low temperature solar heat. Three processes were investigated: (i) a gasification reactor followed by a conventional water-gas shift section and a 
pressure swing absorber, (ii) a gasification reactor followed by an integrated membrane water-gas shift reactor, (iii) a supercritical gasification reactor followed by two flash separators and a pressure swing adsorber. On exergy basis, solar integration on process (ii) was the most efficient for any biomass moisture content. Li et al. [14] studied an ICE-Combined Cooling Heating and Power (CCHP) system driven by the solar/autothermal hybrid gasifier (SAHG) with an indirectly irradiated two-cavity reactor. A simplified zero dimensional steady-state model was proposed to analyze the effects of the oxygen-to-feedstock and steam-to-feedstock ratios on gasification performance. Then, energy assessment of the SAHG-CCHP plant was conducted. The study showed that the solar hybrid process achieves a yearly average increment of $14.2 \%$ in primary energy ratio under the solar radiation condition of Singapore. Moreover, increments in heat, power, and cooling of $19.5 \%, 23.8 \%$, and $4.5 \%$, were reached, respectively as compared to autothermal gasification. Following the same approach, Wang et al. [15] proposed a novel CCHP system based on solar thermal biomass gasification. The influence of key parameters such as the electric load ratio and the solar direct normal irradiance in the off-design work conditions on the thermodynamic performances were analyzed. The study showed that the increasing ratio of heating value of product gas based on the solar thermal biomass gasification reaches $55.09 \%$ as compared to autothermal processes. The biomass saving ratios were approximately $9.22 \%$ and $2.02 \%$ in the cooling and heating modes respectively. A novel solar hybridized dual fluidized bed (DFB) gasification process for FT liquids production was investigated by Guo et al. [16]. This process used inert particles in the solar receiver to absorb, store and transfer the solar heat to the reaction zone despite the solar resource variability. The process was simulated using a pseudo-dynamic model for one-year using hourly-integrated solar insolation time series. The annual energetic and environmental performance of the plant was assessed as function of the solar multiple, the bed material storage capacity, the assumed char conversion and the solar resource. Bai et al [17] investigated the thermodynamic and economic performance of a solar-biomass gasification system for the production of methanol and electricity. In this work, the produced syngas was fed into a methanol synthesis reactor while the un-reacted syngas and the system waste heat were utilized via a combined cycle to generate electricity. The on-design energy efficiency of the system reached $51.89 \%$ with an exergy efficiency of $51.23 \%$. The levelized cost of methanol was $361.88 \$ /$ ton.

Despite solar energy variability, solar gasification plants models were based to date on steady state and pseudodynamic approaches that neglect process transients. However, as previously emphasized by Saw et al. [18], such models dramatically misestimate the performance, the size and the costs of the plants. Therefore, to achieve a higher degree of relevance, transitional regimes due to large and small parasitic variations of incident solar flux should be integrated in the modelling. Moreover, to cope with the variable nature of solar energy, transient feeding management strategies that precisely control the biomass, steam and oxygen flow rates based on the 
reactor temperature, syngas demand and optimal use of solar energy need to be investigated. The objective of this study is the dynamic modelling of a windowed solar reactor devoted to steam biomass gasification. A dynamic model was formulated based on unsteady mass and energy conservation equations coupled to calculated chemical equilibrium. The time evolutions of the reactor temperature, reactants and products flow rates were determined during three consecutive days at Odeillo in France using representative solar irradiation data. Three biomass, steam and oxygen injection scenarios applying continuous feeding control were discussed to study their impact on the thermochemical behavior of the reactor. The dynamic modelling was first applied to a $1.5 \mathrm{~kW}$-scale reactor built and tested in PROMES/CNRS laboratory for experimental validation and then to an industrial reactor for large MW-scale continuous and controlled syngas production.

\section{Experimental set up}

The reactor was settled at the focus of a face down parabolic solar furnace located at the $6^{\text {th }}$ floor of the CNRSPROMES building (Figure 1). The top of the reactor was composed of an aperture that lets the concentrated solar rays enter the metallic cavity. All along the experiments, a sun tracking heliostat was used to reflect the solar rays towards a parabolic mirror that in turn concentrates the radiations towards the reactor aperture. The direct normal irradiance (DNI) was measured all along the experiments by a pyrheliometer every $0.8 \mathrm{~s}$

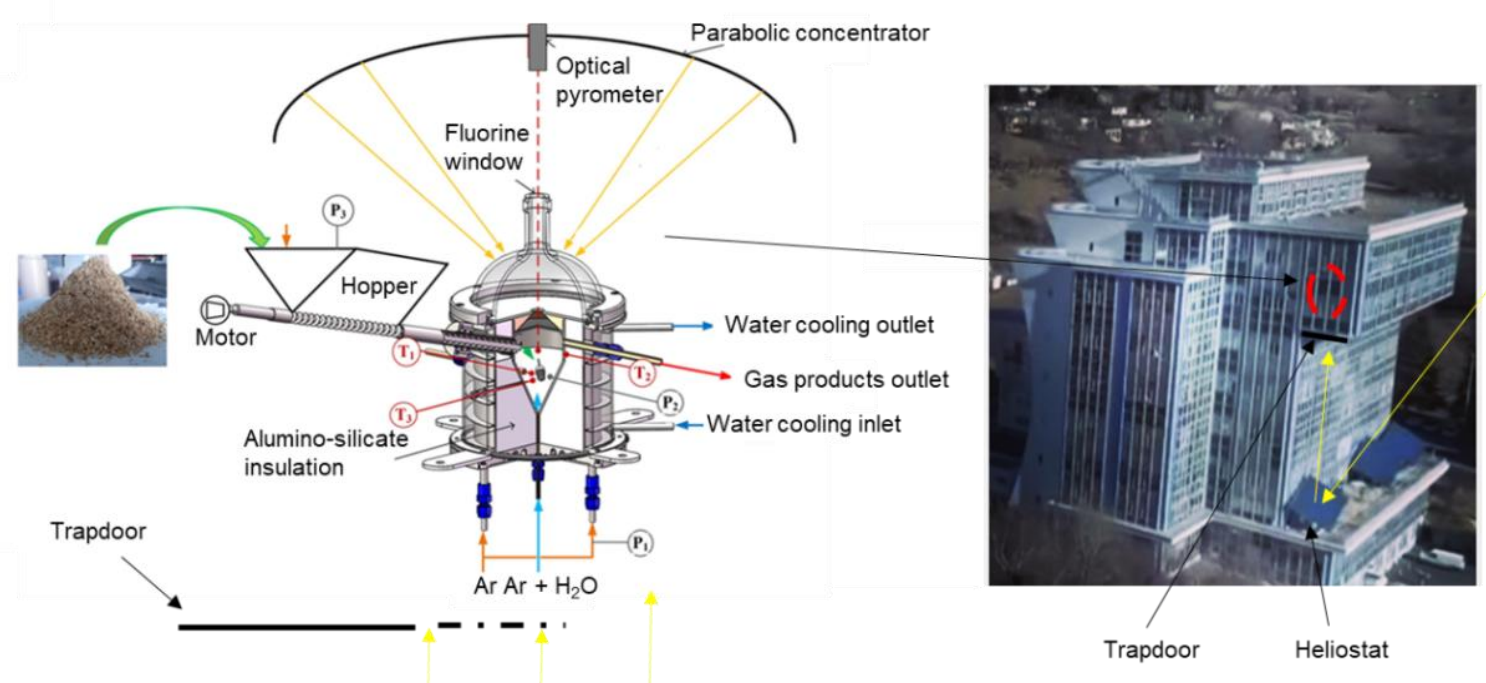

Figure 1. Studied solar gasification reactor at the focus of a vertical-axis parabolic concentrator for allothermal or hybrid solar/combustion operation. 
The feedstock was stored in a hopper $(1.15 \mathrm{~L}$ capacity) and then transported by a screw driven by a motor fixed to the hopper. The gasified millimetric beech wood particles characteristics are summarized in Table 1.

Table 1. Biomass characteristics

\begin{tabular}{cccccccccc}
\hline $\begin{array}{c}\mathrm{C} \\
(\text { wt.\% })\end{array}$ & $\begin{array}{c}\mathrm{H} \\
(\text { wt.\% })\end{array}$ & $\begin{array}{c}\mathrm{O} \\
(\text { wt.\% })\end{array}$ & $\begin{array}{c}\mathrm{N} \\
(\mathrm{wt} \%)\end{array}$ & $\begin{array}{c}\mathrm{S} \\
(\mathrm{wt} \%)\end{array}$ & $\begin{array}{c}\text { Ash } \\
(\text { wt.\% })\end{array}$ & $\begin{array}{c}\text { Moisture } \\
(\mathrm{wt} \%)\end{array}$ & $\begin{array}{c}\text { Density } \\
\left(\mathrm{kg} / \mathrm{m}^{3}\right)\end{array}$ & $\begin{array}{c}\text { Specific } \\
\text { heat } \\
\left(\mathrm{J} / \mathrm{kg} .{ }^{\circ} \mathrm{C}\right)\end{array}$ \\
\hline Beech wood & 48.3 & 6.7 & 44.4 & 0.1 & $<0.1 \%$ & 0.46 & 8 & 650 & 1500 \\
\hline
\end{tabular}

An Ar flow (0.5 NL/min) was continuously injected in the hopper so that the hot gases from the cavity cannot interact with the reactive load. Moreover, to prevent the reactor from window fouling and overheating, a protective Ar flow ( $2 \mathrm{NL} / \mathrm{min}$ ) was constantly injected from the bottom to sweep the window away and make sure that all the gases exit the reactor through the outlet. The jet gases (Ar and steam) were injected from a bottom alumina tube ( $2 \mathrm{~mm}$ inner diameter). They were composed of $0.2 \mathrm{NL} / \mathrm{min}$ of Ar and $200 \mathrm{mg} / \mathrm{min}$ of steam thus providing a slightly over-stoichiometric Steam-to-Biomass (S/B) ratio. The beech wood particles continuously fell into the conical cavity to get mixed with the entering oxidant and carrier gas.

The outlet gas flew through a bubbler and micro-filter to remove excess steam and entrained char particles from the produced syngas. To analyze the syngas composition, an on-line analyzer (GEIT 3100) measured continuously every $3 \mathrm{~s}$ the main species contained in the syngas $\left(\mathrm{H}_{2}, \mathrm{CO}, \mathrm{CO}_{2}\right.$ and $\left.\mathrm{CH}_{4}\right)$. Then, a gas chromatograph equipped with two columns using Ar as carrier gas (micro GC, Varian CP4900) was used to check and confirm the on-line analyzer measurements. The reactor temperature was measured by B-type thermocouples inserted inside the conical part of the cavity (T1 at the cavity center and T3 near the bottom of the cavity in the conical region) and at the external cavity surface (T2). Their tips were protected from the reacting gases with an alumina shielding tube. Three pressure measurements were set in the window area (P1), cavity (P2), and hopper (P3) (Figure 1). A Venturi vacuum pump placed at the end of the outlet tube was used to control and maintain the reactor pressure below 1 bar ( $\sim 0.85$ bar for atmospheric pressure at site elevation) throughout the experiments. All the obtained data were controlled and collected by an automated data acquisition system (BECKHOFF). 


\section{Model development}

\subsection{General principle}

The system of differential equations was derived from the unsteady mass and energy conservation equations written for a perfectly stirred reactor considered isothermal. In fact, the blackbody behavior of cavity receivers tends to homogenize the temperature of the reactor walls. The reaction model was taken into account with a chemical equilibrium model. The reactor model was coded in Python 3. It takes as inputs geometrical features (such as the volume of the reactor, thickness of the cavity walls and insulation, aperture size, etc.), DNI (Direct Normal Irradiance) real time data and the sun's position in the sky represented by both azimuthal $(\gamma)$ and zenith $(\alpha)$ angles. The latter parameters are relevant to properly model the received solar power during dynamic heating and cooling periods. The Meteonorm(C) software was used to generate the solar data with a time step of $15 \mathrm{~min}$. The solving of the dynamic equations was performed with the root function of the Python Scipy library. This function is used to find the roots of systems of equations. Among the available methods, the "hybr" method uses the modified Powell method [19], which has shown the best performance in terms of stability for the calculations.

\subsection{Model parameters}

The solar cavity receiver was machined in a high-temperature resistant metallic FeCrAl alloy. The 0.24 L cavity was pierced at the bottom to allow the passage of an alumina inlet tube of $2 \mathrm{~mm}$ inside diameter from which the oxidizing agent was injected. The whole cavity was insulated by a $30 \mathrm{~mm}$-thick layer of porous ceramic fiber made of $\mathrm{SiO}_{2}$ and $\mathrm{Al}_{2} \mathrm{O}_{3}$. The top of the metallic cavity was lined with an alumina cap (20 mm diameter aperture) to reduce heat losses. To protect the alumina cap from the direct high-flux solar radiation and minimize radiation losses, a $2 \mathrm{~mm}$ layer of zirconia felt and a protective graphite plate were placed above. The feedstock was continuously injected by a screw feeder. The whole feeding system was hermetically fixed to the reactor shell that was water-cooled. Table 2 summarizes the main reactor materials and their physical properties. 
Table 2. Main reactor materials and physical properties

\begin{tabular}{lcccc}
\hline \multicolumn{1}{c}{ Component } & Density, $\rho\left(\mathrm{kg} / \mathrm{m}^{3}\right)$ & $\begin{array}{c}\text { Specific heat, } \mathrm{c}_{\mathrm{p}} \\
\left(\mathrm{kJ} / \mathrm{kg} .{ }^{\circ} \mathrm{C}\right)\end{array}$ & $\begin{array}{c}\text { Thermal } \\
\text { conductivity, } \lambda \\
\left(\mathrm{W} / \mathrm{m}^{2} .{ }^{\circ} \mathrm{C}\right)\end{array}$ & Emissivity, $\varepsilon$ \\
\hline Alumina cap & 4000 & 795 & 7 & 0.80 \\
\hline FeCrAl alloy & 7100 & 800 & 35 & 0.97 \\
\hline Insulation & 400 & 800 & 2.22 & - \\
\hline Zirconia layer & 5700 & 500 & 25 & -
\end{tabular}

After model validation with the lab-scale reactor, the dynamic model was further applied to predict the performance of a scaled up reactor. To extrapolate the reactor, the solar power received by the reactor was first defined as $\mathrm{Q}_{\text {solar }}=10 \mathrm{MW}$ (neglecting optical losses). The concentration ratio (C) was taken equal to 3000 . This value was also used previously [20] as it offers a good compromise between performance and technological accessibility in large-scale concentrating solar power plants. A higher value definitely increases the solar power absorbed by the reactor as radiation losses are reduced, however at the expense of greater costs and complexity, as well as potentially higher optical losses. From these values, the diameter of the aperture was calculated by Eq.2:

$S_{\text {aperture }}=\frac{\pi}{4} D_{\text {aperture }}^{2}=\frac{Q_{\text {solar }}}{C \cdot D N I}$

The ratio between the small-scale cavity diameter and its aperture was held constant during the scale up procedure. The volume of the cavity and its height were sized in order to achieve an average gas residence $\tau$ in the order of a minute, which promotes the gas quality and by the same token the $\mathrm{H}_{2}$ concentration in the syngas [21-22] (indeed at $\mathrm{T}=1200^{\circ} \mathrm{C}, \tau=50 \mathrm{~s}$ at nominal biomass flow rate of $1 \mathrm{t} / \mathrm{h}$ with a slightly over-stoichiometric $\mathrm{S} / \mathrm{B}$ mass ratio of 0.17 and assuming that all the biomass is converted into $\mathrm{H}_{2}$ and $\mathrm{CO}$ ). To estimate the mass of the cavity walls, a constant thickness of $1 \mathrm{~cm}$ was considered. The thickness of the thermal insulation was sized in order to keep a temperature of $50^{\circ} \mathrm{C}$ at the reactor external boundary calculated with an external free convective heat transfer coefficient $\mathrm{h}=10$ $\mathrm{W} / \mathrm{m}^{2} .{ }^{\circ} \mathrm{C}$. Table 3 summarizes the main calculated parameters that were used in the dynamic modelling of the labscale and the large-scale reactor. 
Table 3. Parameters used in the dynamic modelling

\begin{tabular}{lcc}
\hline Parameters & Lab-scale reactor & Large scale reactor \\
\hline $\mathbf{Q}_{\text {solar }}$ & $1.5 \mathrm{~kW}$ & $10 \mathrm{MW}$ \\
\hline $\mathbf{F}_{\text {biomass }}(\mathbf{t} / \mathbf{h})$ & $1.2010^{-5}$ & 1.00 \\
\hline $\mathbf{V}_{\text {cavity }}\left(\mathbf{m}^{\mathbf{3}}\right)$ & $2.4010^{-4}$ & 139.50 \\
\hline $\mathbf{D}_{\text {cavity }}(\mathbf{m})$ & $7.8010^{-2}$ & 6.40 \\
\hline $\mathbf{D}_{\text {aperture }}(\mathbf{m})$ & $2.0010^{-2}$ & 2.06 \\
\hline $\mathbf{m}_{\text {cavity wall }}(\mathbf{k g})$ & $3.5010^{-1}$ & 6218.60 \\
\hline $\mathbf{R}_{\text {cap }}\left({ }^{\circ} \mathbf{C} / \mathbf{W}\right)$ & 4.69 & $2.0010^{-3}$ \\
\hline $\mathbf{R}_{\text {insulation }}\left({ }^{\circ} \mathbf{C} / \mathbf{W}\right)$ & 5.88 & $2.2310^{-2}$ \\
\hline
\end{tabular}

\subsection{Mathematical model formulation}

The general unsteady atomic element balance equation for atoms ' $\mathrm{j}$ ' is given by the following equation (Eq.3):

$$
\frac{d N_{j}}{d t}=\sum_{i=1}^{N C} v_{i j} F_{i}^{i n}-\sum_{i=1}^{N C} v_{i j} y_{i} F^{o u t}
$$

Where $\mathrm{N}_{\mathrm{j}}$ is the number of moles of atoms ' $\mathrm{j}$ ' inside the cavity at time ' $\mathrm{t}$ ', ' $\mathrm{F}$ ' is the molar flow rate (mol/s), 'in' and 'out' indicate the inlet and outlet, respectively. NC is the total number of components (molecules) in the system, $v_{\mathrm{ij}}$ is the stoichiometric coefficient of the " $\mathrm{j}$ " atom in the " $\mathrm{i}$ " molecule, $\mathrm{y}_{\mathrm{i}}$ is the outlet mole fraction of the component "i". In this equation, there is no reaction term because the atoms are conserved.

The syngas composition was calculated at each time step, it was assumed to be equal to that given by chemical equilibrium. As a result, the total number of moles produced for each syngas component was expressed as a function of the atomic composition, temperature and pressure inside the reactor (equal to atmospheric pressure). This relationship is expressed by Eq.4:

$n_{j}=f_{e q}\left(N_{1}, \ldots, N_{k} \ldots, N_{T}, T, P\right)$

The chemical equilibrium model was computed by the Python code and was based on the minimization of the system's Gibbs free energy. The nonlinear optimization problem was solved by the numerical procedure SLSQP (Sequential Least SQuares Programming) of the Scipy library following the approach proposed by Kitchin [23]. 
The gases were assumed to be ideal. The total pressure inside the cavity must remain constant. The ideal gas law (Eq.5) was hence used to calculate the total amount of moles of gaseous species in the reactor $\mathrm{n}_{\mathrm{g}}$.

$n_{g}=\sum_{i=1}^{N C g} n_{i}=\frac{P V_{R e a c t o r}}{R T}$

The energy balance equation (Eq.6) was also solved to predict the reactor temperature. It was applied to the reactor cavity volume (reaction zone) and walls as proposed by Charvin et al. [24] (Figure 2).

$\frac{d E}{d t}=\frac{d\left(U_{w a l l}+\sum_{i=1}^{N C} n_{i} \cdot U_{i}(T)\right)}{d t}=\sum_{i=1}^{N C} F_{i}^{e} h_{i}\left(25^{\circ} C\right)-\sum_{i=1}^{N C} F_{i}^{S} h_{i}(T)+Q_{n e t}$

$Q_{\text {net }}=Q_{\text {solar }}-Q_{\text {rad,aperture }}-Q_{\text {rad,cap }}-Q_{\text {cond,insulation }}$

where $\mathrm{U}$ is the internal energy, $\mathrm{Q}_{\text {solar }}$ is the solar power input, $\mathrm{Q}_{\mathrm{cond}}$ are the losses by conduction through insulation, $\mathrm{Q}_{\text {rad,aperture }}$ are the losses due to re-radiation through the aperture, and $\mathrm{Q}_{\text {rad,cap }}$ are the losses by radiation at the top of the alumina cap.

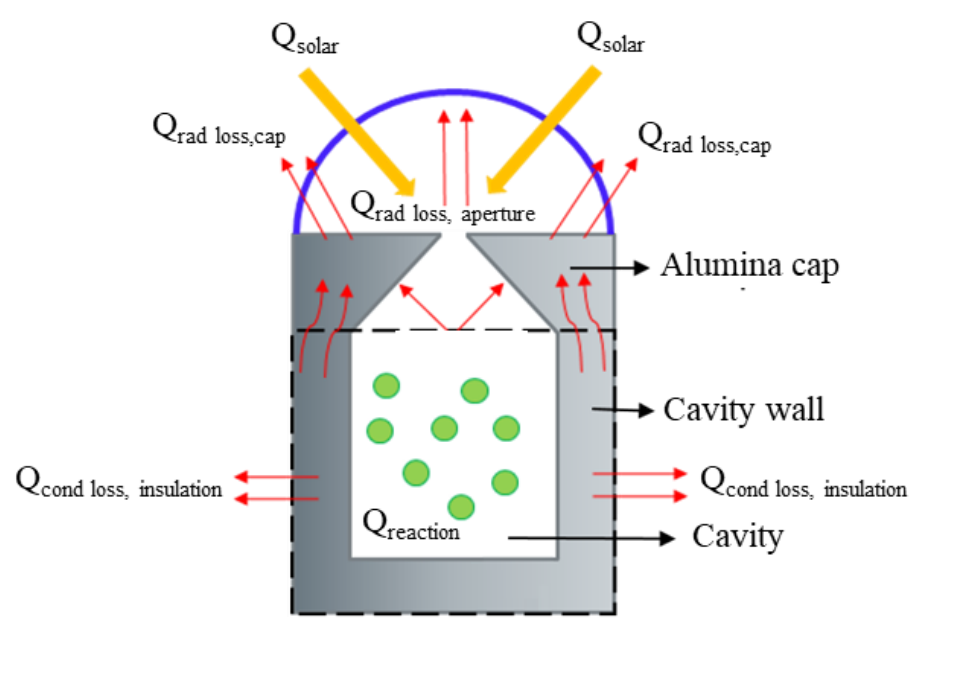

Figure 2. Schematic of the thermochemical reactor model.

$\mathrm{Q}_{\text {solar }}$ was expressed as a function of the concentration ratio C, DNI and optical efficiency $\eta_{\text {optical }}$ as shown in Eq.8.

$Q_{\text {solar }}=$ DNI.C. $A_{\text {aperture }} \cdot \eta_{\text {optical }}$

With $\eta_{\text {optical }}=\eta_{\text {field }}(\gamma, \alpha) \cdot \eta_{\text {beam down }} . \eta_{\text {field }}(\gamma, \alpha)$ was updated at each time step by 2D linear interpolation of the solar field optical matrix generated by the open source code SAM (System Advisor Model) of the NREL. It included cosine 
effects, tracking errors, mirror reflectivity and dirt on mirrors. $\eta_{\text {beam down }}$ took into account energy losses due to secondary reflection on the beam down system. It was assumed equal to 0.92 .

The aperture thermal losses were calculated by Eq.9.

$Q_{\text {rad,aperture }}=A_{\text {aperture }} \sigma\left(T^{4}-T_{\infty}^{4}\right)$

The losses from the alumina cap $\left(\mathrm{Q}_{\mathrm{rad}, \mathrm{cap}}\right)$ were calculated by Eq.10.

$Q_{\text {rad }, \text { cap }}=\varepsilon_{\text {cap }} . A_{\text {cap }} \sigma\left(T_{c a p}{ }^{4}-T_{\infty}^{4}\right)$

The cap effective temperature ( $\left.\mathrm{T}_{\text {cap }}\right)$ was deduced from Eq.11.

$Q_{\text {rad,cap }}=Q_{\text {cond,cap }}+Q_{\text {cavity } \rightarrow \text { cap }}$

$\mathrm{Q}_{\text {cond,cap }}$ is the heat transferred from the cavity walls to the alumina cap by conduction, as expressed by Eq. 12

$Q_{\text {cond }, \text { cap }}=\frac{T-T_{\text {cap }}}{R_{\text {cap }}}$

$\mathrm{Q}_{\text {cavity } \rightarrow \text { cap }}$ is the net radiative power received by the alumina cap from the radiating cavity walls, deduced from

Eq.13.

$Q_{\text {cavity } \rightarrow \text { cap }}=Q_{\text {cavity } \rightarrow S_{\text {top }}}-Q_{\text {rad,aperture }}$

$\mathrm{Q}_{\text {cavity } \rightarrow \text { Stop }}$ is the radiation received by the top of the cavity including the one received by the cap and the aperture. It was calculated by the radiative electrical analogy assuming gray bodies heat exchange and considering the three different surfaces of the cylindrical cavity (up, down and lateral surfaces), as depicted in Figure 2.

The thermal losses through the insulation were deduced from the following equation (Eq.14):

$Q_{\text {cond,insulation }}=\frac{\mathrm{T}-T_{\text {ext }}\left(25^{\circ} \mathrm{C}\right)}{R_{\text {insulation }}}$

\section{Results and discussion}

\subsection{Model validation at $1.5 \mathrm{~kW}$ scale}

To validate the model, the simulation results were compared with experimental data obtained during previous experimental campaigns at $1.5 \mathrm{~kW}$ scale [25-26]. The biomass feed-rate was set at $1.2 \mathrm{~g} / \mathrm{min}$ and the water feed-rate at $0.2 \mathrm{~g} / \mathrm{min}$. The total argon flow rate was kept constant at $2.7 \mathrm{NL} / \mathrm{min}$. The incoming solar power was fixed at 900W, 1200W and 1400W. Simulations were performed using the same boundary and initial conditions until the 
reactor temperature stabilized to reach steady state. Figure 3 shows the steady-state temperature as a function of solar power for the Python model and the measured T3 temperature (inside the cavity).

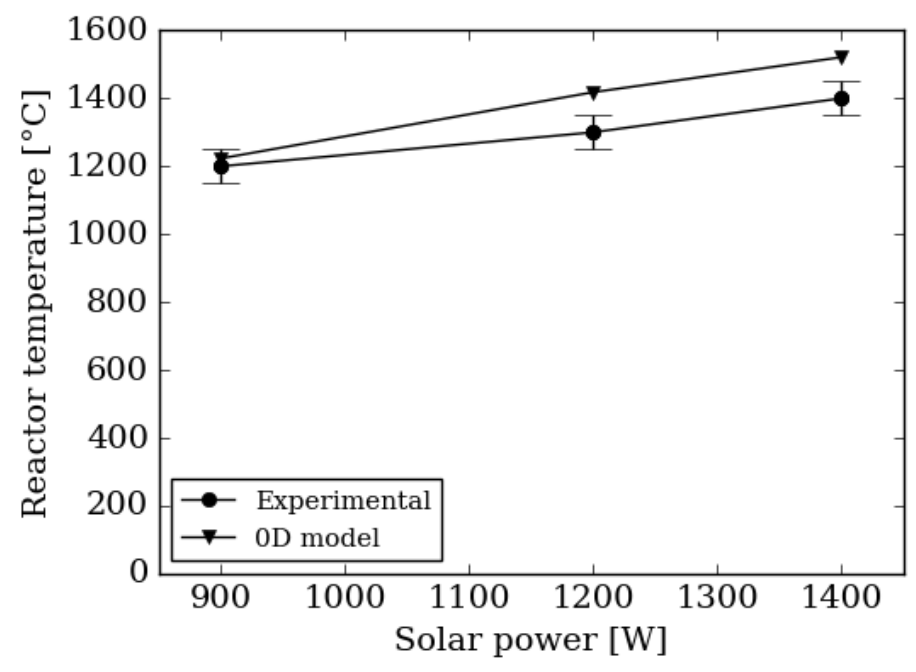

Figure 3. Thermal validation of the model at steady state.

These results show that the model slightly overpredicts the reactor temperature compared to the experiments. This is especially true with high solar power inputs. Indeed, the relative error on temperature as compared to the experiments was $1.9 \%$ at $900 \mathrm{~W}$ and $8.6 \%$ at $1400 \mathrm{~W}$. One possible reason for this is that the thermal losses from the inlet and outlet tubes were not considered in the dynamic (0D) model. However, such losses are not negligible [27]. The dynamic behavior of the model was also evaluated. When the reactor reached $1200{ }^{\circ} \mathrm{C}$, the solar irradiation of the reactor, as well as biomass and steam supplies were interrupted. The argon injection was maintained at 2.7 NL/min. Figure 4 shows a comparison of temperature decrease over time during the reactor cooling phase with an initial temperature of $1200^{\circ} \mathrm{C}$ according to $\mathrm{T} 3$. Values from $\mathrm{T} 2$ (positioned at the external cavity wall) are also plotted. 


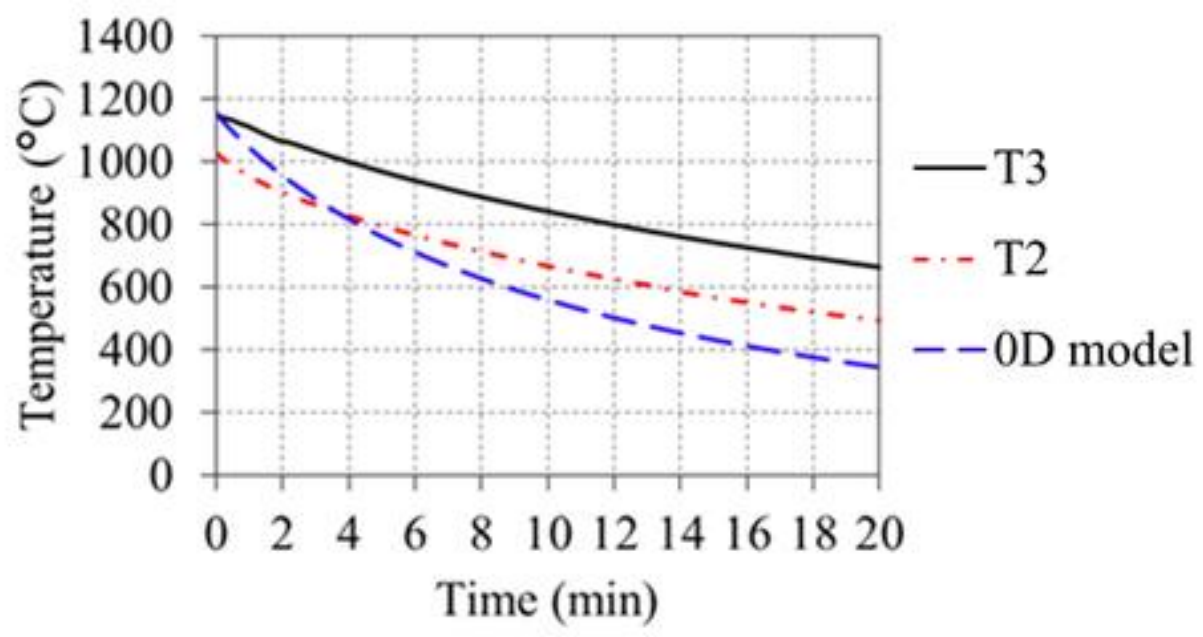

Figure 4. Thermal validation of the dynamic model.

The temperature calculated by the model is in agreement with the results of the T2 thermocouple down to around $800^{\circ} \mathrm{C}$ with a relative error of $8 \%$. The comparison with $\mathrm{T} 3$ shows an increasing difference from the beginning of cooling. This may be related to the fact that T3 is inserted inside the cavity and that the heat transfer from the interior of the cavity to the cold outer shell of the reactor takes much longer. Overall, the model reproduces well the main trends that were observed experimentally regarding the reactor thermal behavior, and it was therefore used to extrapolate the reactor.

The experimentally measured syngas yield was also compared to model predictions based on chemical equilibrium calculations. Notable differences were observed (Figure 5). At $1200^{\circ} \mathrm{C}$, the system composition calculated by the equilibrium model shows that only $\mathrm{H}_{2}$ and $\mathrm{CO}$ were produced, whereas $\mathrm{CH}_{4}$ and $\mathrm{CO}_{2}$ were additionally measured in small amounts during experiments. The Python model composition calculation assumed thermodynamic equilibrium, which is only valid for very long residence times. Actually, the average residence time for the small-scale reactor was estimated to be $0.4 \mathrm{~s}$ (at $1200^{\circ} \mathrm{C}$ ), which means that thermodynamic equilibrium may not be reached, thereby explaining the discrepancy between the calculated and the measured syngas yields. Therefore, kinetic models would be more suitable at this scale. This is confirmed by a previously developed 3D-CFD (Computational Fluid Dynamics) steady-state model based on global chemical kinetics for both pyrolysis and gasification reactions that allowed simulating biomass solar gasification in the studied reactor [27]. The CFD simulation using kinetic models gave more consistent results with a maximum error on syngas molar composition (including $\mathrm{H}_{2}, \mathrm{CO}, \mathrm{CO}_{2}$ and $\mathrm{CH}_{4}$ ) of around $10 \%$ (Figure 5). Due to the targeted high operating temperature and the significantly increased residence times ( $\sim 50 \mathrm{~s})$ for the scaled-up reactor, the chemical equilibrium assumption appeared better justified in this case and was thus used in the following. 


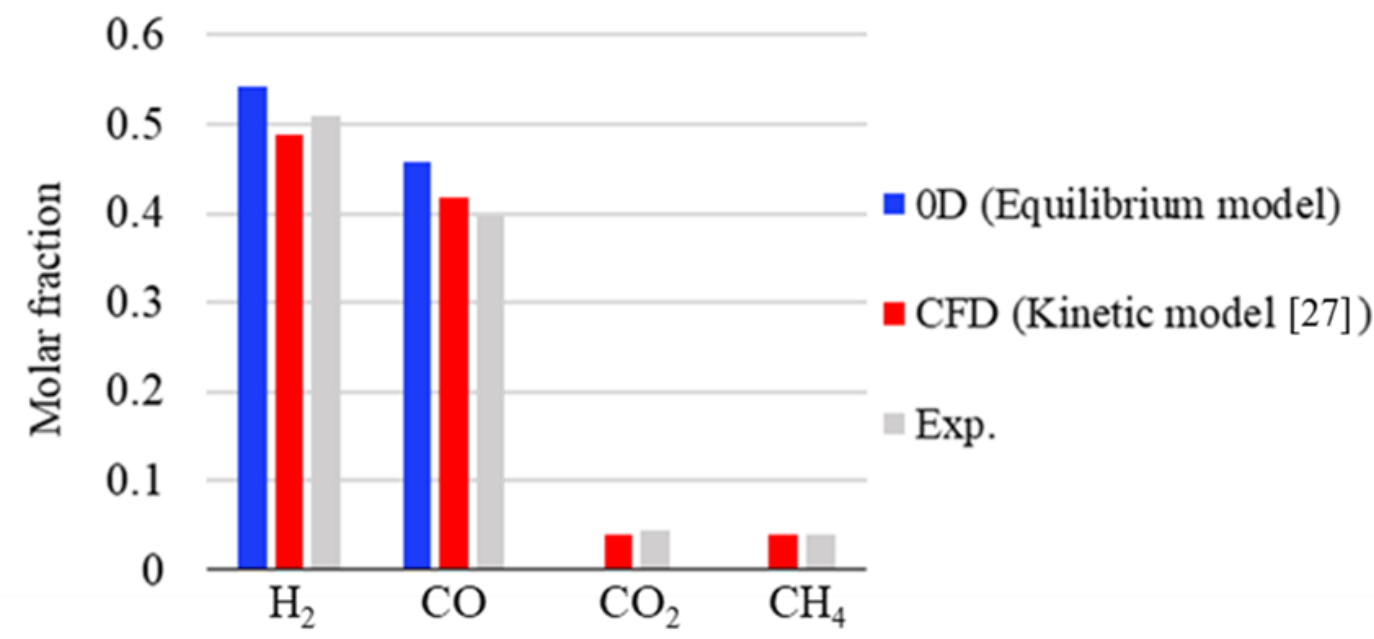

Figure 5. Comparison of syngas composition calculated by the 0D chemical equilibrium model, 3D CFD model and experimentally measured values.

\subsection{Large-scale reactor simulation}

Dynamic simulations of the large-scale reactor were conducted using real solar data (averaged over a 19-year period: 1991-2010) of three consecutive days $\left(4^{\text {th }}, 5^{\text {th }}\right.$ and $6^{\text {th }}$ of May in Figure 6). These DNI data were generated by the commercial software Meteonorm $\odot$ and the yearly variability of DNI at Odeillo for the selected period was 2.5\%. Three feeding management strategies were compared. The first one (TOR) is a simple on/off control algorithm. The second one (OPTI) tunes the biomass and steam flow rates in order to thermally stabilize the reactor temperature at $1200^{\circ} \mathrm{C}$. The third mode (HYB) uses pure oxygen and an additional extra-biomass injection to overcome solar energy fluctuations, thus insuring a continuous day and night conversion of biomass. The three feeding modes are discussed in the following sections. For all the simulations, the selected S/B mass ratio was 0.17. The solar-to-fuel efficiency (SFE) was used to discuss the performances of the reactor. This metric expresses the ratio of the calorific value contained in the syngas over the total power input that enters the reactor in the form of both solar power and biomass calorific value. When the available solar power is equal to zero, the SFE is equivalent to the Cold Gas Efficiency (CGE). 


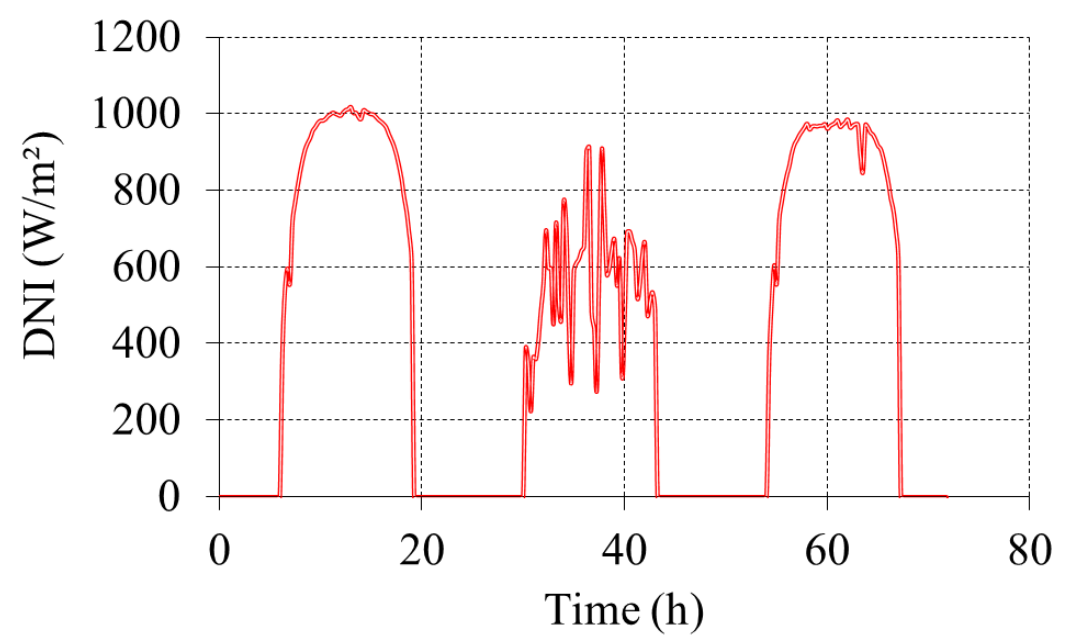

Figure 6. Available averaged DNI for three consecutive days $\left(4^{\text {th }}, 5^{\text {th }}\right.$ and $6^{\text {th }}$ of May).

\subsubsection{TOR allothermal control mode (on/off control)}

In this operating mode, both biomass and steam started being injected when the temperature exceeds an upper threshold. Their injection was still maintained if the temperature dropped below this threshold but it was stopped when the temperature fell below a lower limit. The chosen upper and lower limits were $1250^{\circ} \mathrm{C}$ and $1150^{\circ} \mathrm{C}$, respectively. There were two main operating steps: one for heating the reactor and the other for gasifying the biomass. During the first step, the only injected gas was the inert carrier gas (Ar for the small-scale reactor and $\mathrm{N}_{2}$ for the large-scale reactor). Once the temperature reached $1250^{\circ} \mathrm{C}$, biomass and steam were fed at a constant nominal flow rate; the reactor temperature fluctuations were this way solely due to solar energy variations. If, during operation, the temperature decreased below $1150^{\circ} \mathrm{C}$, the supplies, except for inert gas, were stopped. During the cooling at night, the top of the reactor was covered to avoid radiation losses from the aperture and the front cover, so as to minimize the heat losses. To study the impact of the biomass and steam nominal flow rates on the reactor behavior, three biomass feeding rates were selected: $0.5 \mathrm{t} / \mathrm{h}, 1 \mathrm{t} / \mathrm{h}$ and $2 \mathrm{t} / \mathrm{h}$. Figure 7 shows the reactor temperature for the three feeding rates as well as the solar power input. 


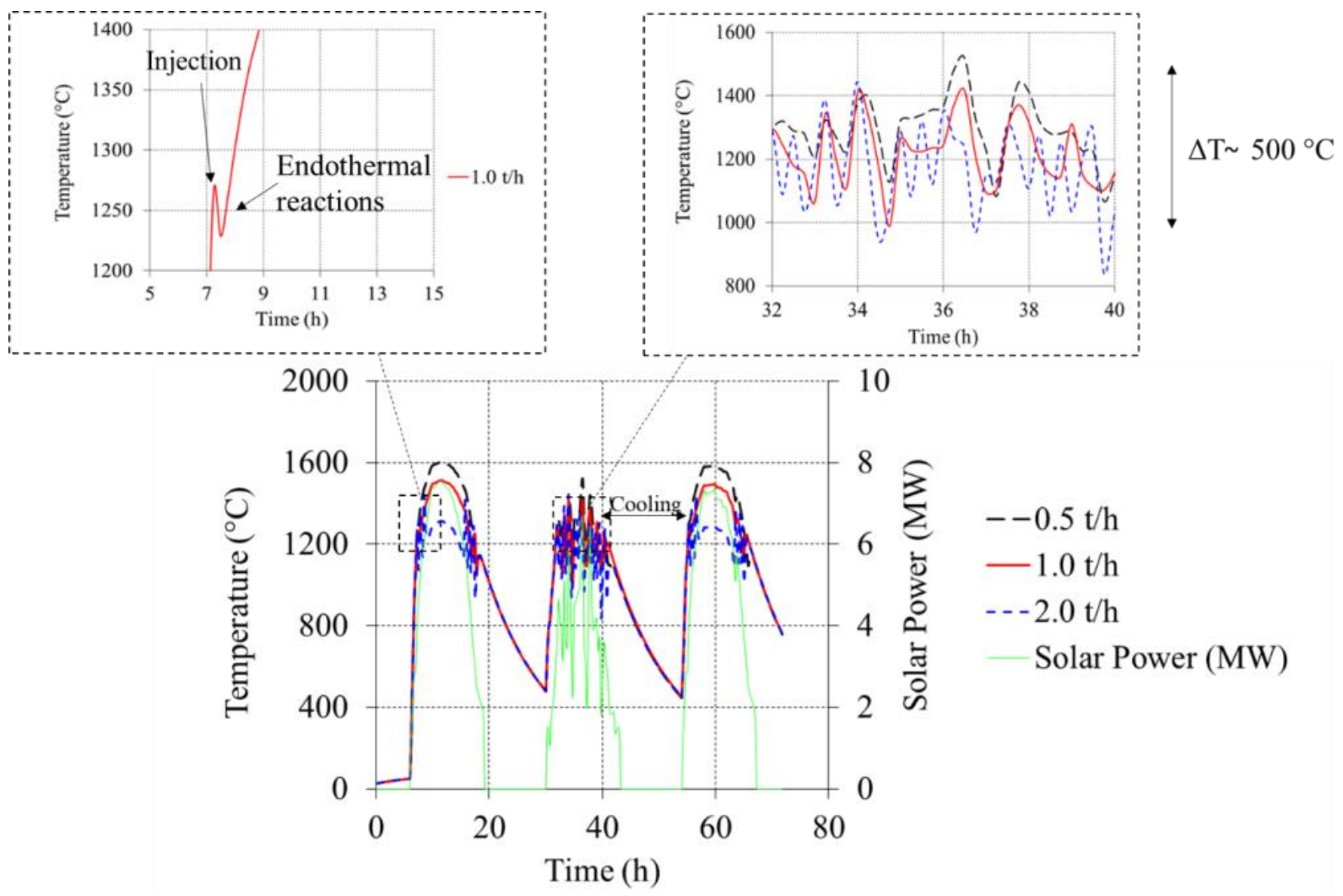

Figure 7. Received solar power and reactor temperature evolution for three biomass feeding rates $(0.5 \mathrm{t} / \mathrm{h}, 1 \mathrm{t} / \mathrm{h}, 2 \mathrm{t} / \mathrm{h})$

The different cooling and heating phases of the reactor are clearly distinguished. The model predicts a duration for reactor heating in the morning between $1 \mathrm{~h}$ (heating rate of $20^{\circ} \mathrm{C} / \mathrm{min}$ ) for days 1 and 3 and $1 \mathrm{~h} 30$ (heating rate of $13^{\circ} \mathrm{C} / \mathrm{min}$ ) for day 2 . This duration is extremely dependent on the concentration ratio $\mathrm{C}$, the DNI and the quality of the solar collection represented here by the optical efficiency $\left(\eta_{\text {optical }}\right)$. It should be kept in mind that the reactor thermal inertia was exclusively represented by the reactor walls and reaction zone. Hence, this heating duration may be longer because it does not take into account the heating of other reactor components such as the piping and the insulation. Nevertheless, at first approximation, it can be observed that the choice of the nominal biomass flow rate has a strong influence on the reactor crest temperature $\left(1600^{\circ} \mathrm{C}\right.$ for $0.5 \mathrm{t} / \mathrm{h}, 1510^{\circ} \mathrm{C}$ for $1 \mathrm{t} / \mathrm{h}$ and $1310^{\circ} \mathrm{C}$ for $2 \mathrm{t} / \mathrm{h}$ ). The minimum achieved temperature during the cooling phase was around $500^{\circ} \mathrm{C}$ whatever the feeding rates. The second day of the simulation was very cloudy with high fluctuations in DNI, which lead to sharp temperature variations and frequent shutdown and starting up of the installation (Figure 8). While the lowest feeding rate $(0.5 \mathrm{t} / \mathrm{h})$ allowed converting continuously the biomass with very rare interruptions, the number of interruptions went up from 6 to 12 by increasing the biomass flow rate. 


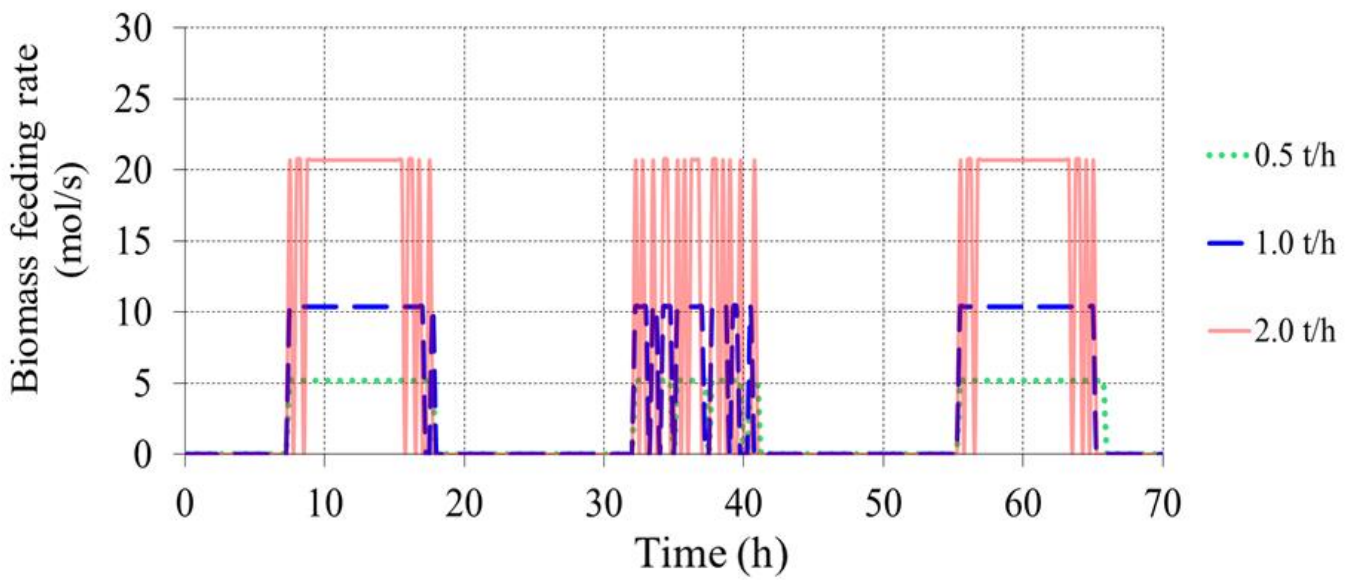

Figure 8. On/off control of the biomass feeding rate

The time averaged SFE (integrated over the three days) attained for $0.5 \mathrm{t} / \mathrm{h}, 1 \mathrm{t} / \mathrm{h}$ and $2 \mathrm{t} / \mathrm{h}$ was $35 \%, 51 \%$, and $54 \%$, respectively. In fact, as the biomass feeding rate was increased (from $0.5 \mathrm{t} / \mathrm{h}$ to $2.0 \mathrm{t} / \mathrm{h}$ ), the reactor temperature decreased due to the sensible heating of the reactants, vaporization of the biomass moisture and endothermal pyro-gasification reaction, therefore, the reactor thermal losses were lower leading to greater SFE. This proves that feeding rates up to $2 \mathrm{t} / \mathrm{h}$ improve the use of solar energy, however at the expense of process stability issues. Higher flow-rates were not investigated as the solar power was not sufficient. Therefore, to make full use of solar energy, minimize the heat losses, thermally stabilize the reactor and guarantee high syngas quality, an optimized control mode of the biomass and steam feeding rates was proposed.

\subsubsection{OPTI allothermal control mode (Optimized)}

In this mode, the lower and upper limits for biomass and steam injections were similar to that of the TOR mode values. The feeding flow rates were controlled in such a way that a temperature of $1200^{\circ} \mathrm{C}$ was maintained as long as possible. The process down time occurred when the biomass supply to maintain the reactor at $1200^{\circ} \mathrm{C}$ was less than $5 \%$ of the nominal flow rate (assumed here to be $1 \mathrm{t} / \mathrm{h}$ ). The biomass feeding rate control was done by solving an optimization problem (Eq. 15). The biomass flow rate, $\mathrm{F}_{\text {biomass, }}$, was calculated in order to minimize the difference between the reactor temperature, $\mathrm{T}$, and the setpoint temperature $\mathrm{T}_{\mathrm{C}}$ while the $\mathrm{S} / \mathrm{B}$ ratio is held constant. To achieve this optimization, the secant method was applied using the newton function of the Scipy 
library. The biomass and steam feeding rates were hence calculated to ensure a fixed temperature $\mathrm{T}_{\mathrm{C}}=1200^{\circ} \mathrm{C}$ as depicted in Eq.15.

$T\left(F_{\text {biomass }}\right)=T_{c}$

The achieved temperature during the three days for the OPTI and TOR operations is depicted in Figure 9.

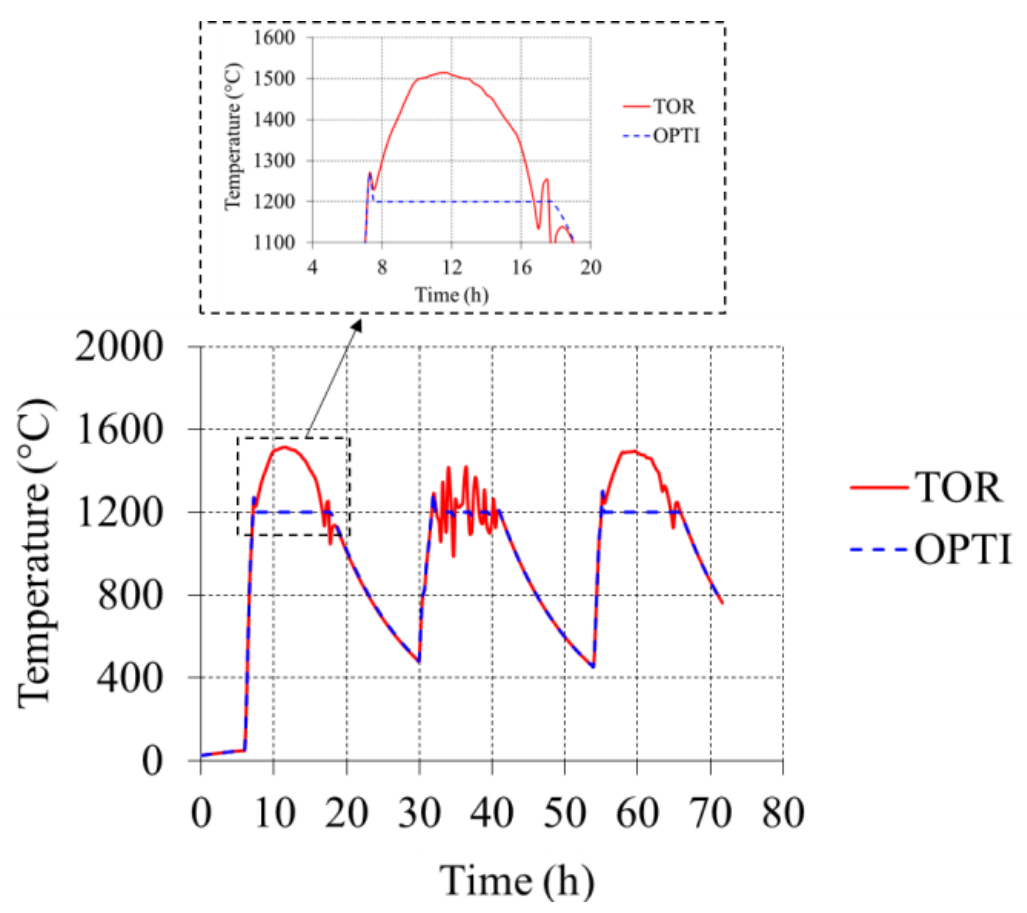

Figure 9. Temperature profiles for the TOR and OPTI control modes

It was observed that the OPTI mode efficiently stabilized the reactor temperature at $1200^{\circ} \mathrm{C}$ avoiding any system sudden shut down and allowing a smooth and controlled variation of the biomass and steam flow rates. The OPTI scenario also avoided unnecessary reactor overheating that lowers the thermal losses. In addition, the observed sharp variations in temperature depicted in Figure 7 during the TOR allothermal operation were eliminated. The calculated biomass feeding rate is given in Figure 10-a, and the resulting $\mathrm{H}_{2}, \mathrm{CO}$ and $\mathrm{CO}_{2}$ production rates are depicted in Figure 10-b. Tars and light hydrocarbons content was negligible due to the high gasification temperature. 


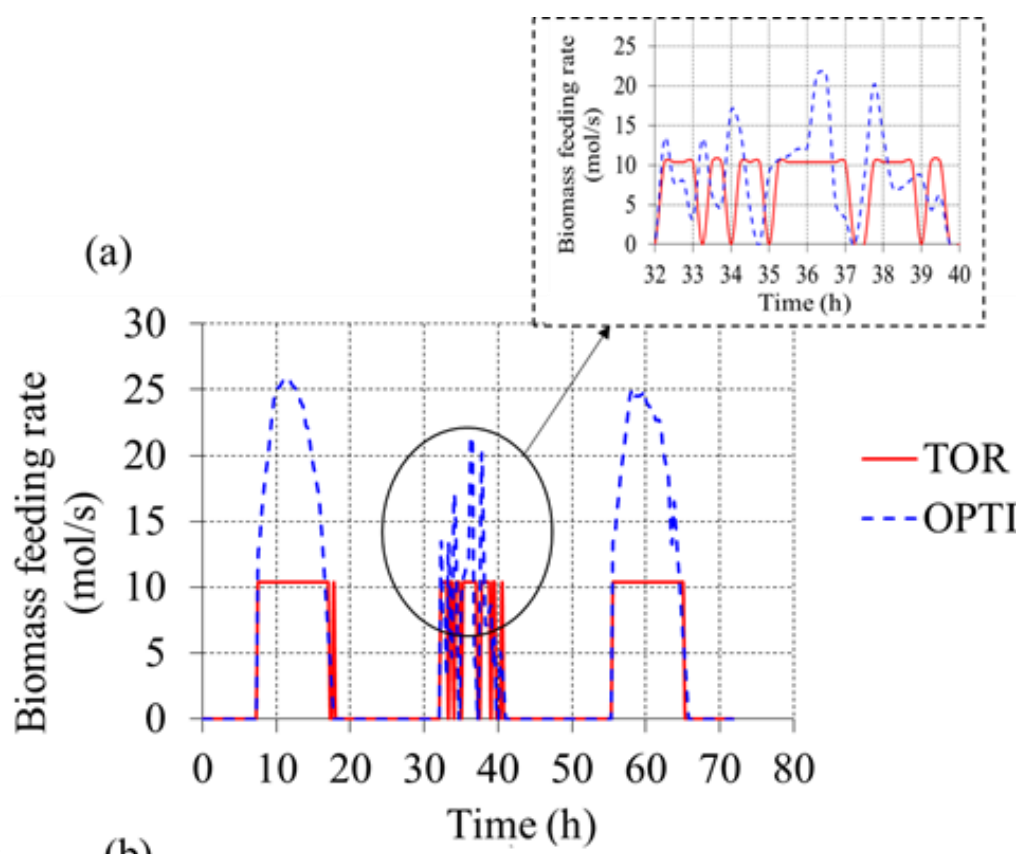

(b)

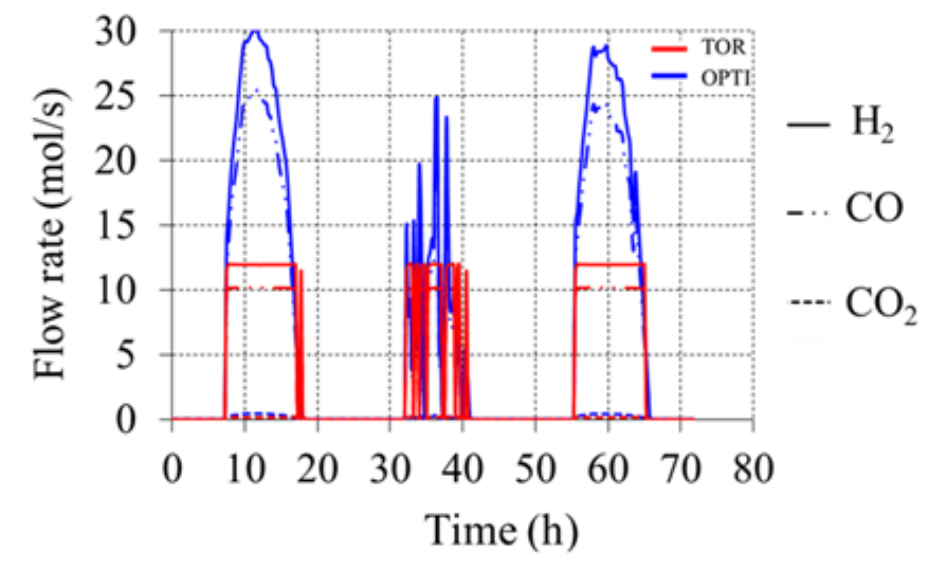

Figure 10. Evolution of (a) biomass feeding rate and (b) syngas yields for the TOR and OPTI models

The model predicts that the synthesis gas total production is increased three-fold for the OPTI mode with a syngas composition that remains almost the same as for the TOR operation. The time-dependent SFE is plotted in Figure 11. The OPTI mode increases the SFE from $51 \%$ to $78 \%$ (by $53 \%$ ) during sunny days at noon. This is due to the significant increase in reactor productivity and the marked reduction of heat losses. It is also noted that during cloudy days, both OPTI and TOR modes show difficulties to operate, thereby resulting in a marked drop in the production yield. To tackle this limitation and to warrant a consistent biomass conversion, process hybridization through combined solar heating and partial feedstock oxy-combustion was proposed. The technical feasibility of 
the hybrid solar/combustion process was first investigated on the small-scale reactor and $\mathrm{O}_{2}$ injection during sunlacking periods was successful to elevate the reactor temperature [28]. Following these first results, the HYB mode was used to counteract solar energy fluctuations for the large-scale reactor while enabling an optimized allothermal biomass conversion during sunny periods.

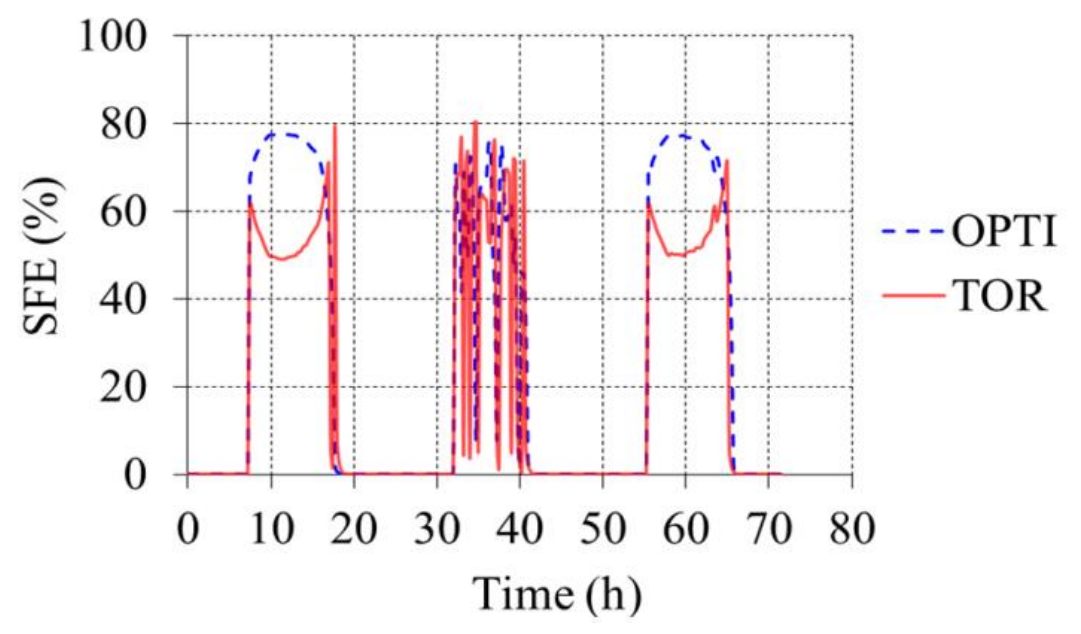

Figure 11. SFE for the TOR and OPTI control modes

\subsubsection{HYB control mode (Hybrid)}

This mode consisted in using OPTI mode when there was sufficient sunlight, otherwise a controlled injection of extra-biomass and stoichiometric pure oxygen was used for partial feedstock combustion to supply the reactor with the missing thermal energy. For studying the HYB mode, the minimum biomass flow rate aimed at being steam solar-gasified was $1 \mathrm{t} / \mathrm{h}$. Hence, when the amount of solar energy was unable to steam gasify $1 \mathrm{t} / \mathrm{h}$, an additional amount of biomass and pure oxygen was fed into the reactor to assist the solar heating. This way, the gasification temperature was maintained at $1200^{\circ} \mathrm{C}$ all day long. To minimize the energy losses, the top of the reactor was covered when radiation losses became equal to or higher than the entering solar power. To calculate the extra-biomass injection flow rate, a similar approach to that used in the OPTI mode was applied (Eq.15). The difference is that instead of calculating the biomass flow rate for gasification, it corresponds to the extra-injection of biomass. The resulting temperature profile is plotted in Figure 12. 


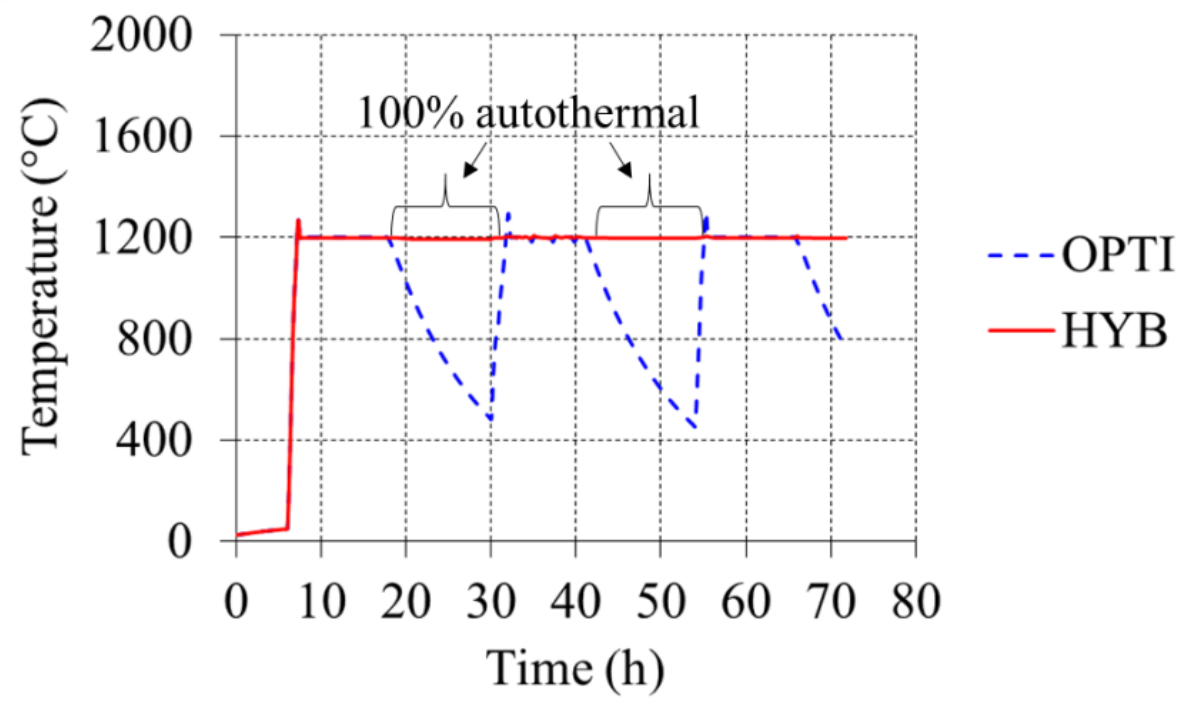

Figure 12. Temperature evolution profiles for the OPTI and HYB control modes

It can be seen that transient periods and temperature drops due to cooling at night are eliminated by gradually switching to a full autothermal mode. A constant and stable temperature was this way achieved. In the OPTI and HYB operation modes, the inlet feeding rates were varying parameters calculated dynamically by the solver to stabilize the reactor temperature. Figure 13-a shows the calculated biomass, steam and oxygen inlet flow rates to accommodate the variable solar flux during day and night operation and Figure 13-b shows the main syngas production rates as a function of time. 
(a)
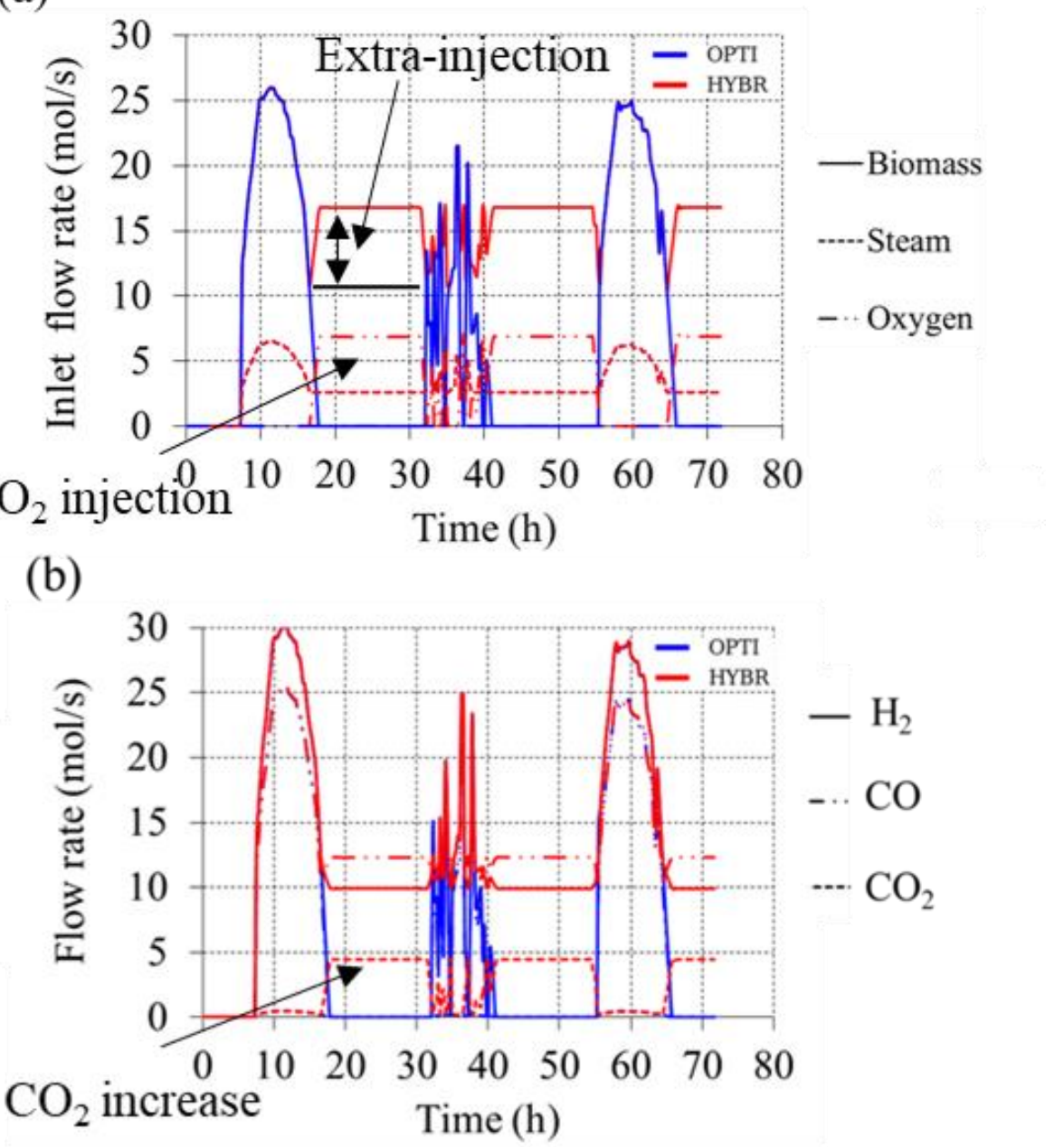

Figure 13. Evolution of (a) inlet reactants flow rates and (b) syngas production rates for the OPTI and HYB control modes

The results show that oxygen injection took place only at the end of the day for days 1 and 3 . The maximum percentage of biomass combusted was around $38 \%$ to operate the reactor in autothermal mode $(6.5 \mathrm{~mol} / \mathrm{s}$ of dry biomass). Accordingly, a SFE (i.e. Cold Gas Efficiency since $\mathrm{Q}_{\text {solar }}=0 \mathrm{~W}$ ) of $80 \%$ was calculated during the autothermal operation. For the second day, oxygen was injected all the time due to the low solar input. A considerable gain was achieved in terms of syngas yield as compared to the OPTI mode. Indeed, the total amounts of $\mathrm{H}_{2}$ and $\mathrm{CO}$ were respectively $1957 \mathrm{kmol}$ and $1656 \mathrm{kmol}$ for the OPTI mode; they increased by $71 \%$ and $104 \%$ in the HYB mode to reach $3349 \mathrm{kmol}$ of $\mathrm{H}_{2}$ and $3388 \mathrm{kmol}$ of $\mathrm{CO}$. Nonetheless, the syngas composition was significantly impaired. The $\mathrm{H}_{2}: \mathrm{CO}$ ratio dropped from 1.2 during the solar-only operation to 
0.80 in the full autothermal mode. The $\mathrm{CO}_{2}$ production rate also increased notably from around $1 \mathrm{~mol} / \mathrm{s}$ during the solar-only operation to $4.9 \mathrm{~mol} / \mathrm{s}$ at night.

\section{Conclusions}

A dynamic model of solar gasification reactor was developed to determine the temperature and syngas products evolution during continuous operation in both solar-only (allothermal) and hybrid solar/autothermal modes. With the aim of achieving higher syngas productivity and better use of solar energy during solar-aided steam gasification, three reactants feeding management strategies (TOR, OPTI and HYB) were proposed and discussed to run a $10 \mathrm{MW}_{\text {solar }}$ solar gasification plant. Accordingly, the importance of biomass and oxidants flow rates real time monitoring and dynamic control was emphasized. The following conclusions were drawn:

(i) The TOR mode gasified a constant mass flow rate of biomass when the reactor temperature was above a fixed setpoint value. This mode suffered from significant heat losses due to reactor overheating and large temperature variations. The latter should be alleviated as they may potentially damage the reactor materials.

(ii) The OPTI mode was then considered to overcome TOR issues by stabilizing the reactor temperature at a setpoint value, which reduced considerably the heat losses, while limiting the reactor overheating and increasing the syngas yield. However, both TOR and OPTI modes showed a considerable drop in syngas production during cloudy days.

(iii) The HYB mode coupled the OPTI algorithm during sunny periods with a smart injection of biomass and oxygen for partial feedstock combustion to supply the reactor with the deficient process heat. This allowed to counteract sharp DNI variations and ensured a minimum continuous production of $\mathrm{H}_{2}$ and $\mathrm{CO}$ at nights and during cloudy periods. The gradual addition of oxygen to the system impaired the syngas composition by reducing the $\mathrm{H}_{2}$ : $\mathrm{CO}$ ratio and by increasing the $\mathrm{CO}_{2}$ content.

The varying syngas composition (especially during hybrid operation) can lead to complications in the gas purification and downstream chemical conversion processes of the produced syngas. Thus, the composition should be adjusted and levelled throughout the operation. To achieve an optimal and stable $\mathrm{H}_{2}: \mathrm{CO}$ ratio, a permanent and dynamic coupling of the solar gasification reactor with other hydrogen production processes such as electrolysis and steam methane reforming may be relevant. Another alternative to upgrade the syngas is the utilization of a Water-Gas Shift (WGS) reactor that dynamically fixes the syngas composition to a set-point value [29]. Very little empirical results are available in this field and the dynamic coupling between the different unit operations is still in its infancy. 
The dynamic control of these solar reactors appears to be feasible and the development of intelligent algorithms plays a key role to cope with solar energy fluctuations. Short-term forecasts and accurate forecasts of DNI are vital to correctly apprehend the highly variable solar flux, which constitutes an additional challenge that still needs to be addressed.

Finally, the developed model can be used for dynamic process simulations to predict the annual performance of large-scale solar gasification plants.

\section{Acknowledgements}

This study was financially supported by ADEME (French Environment and Energy Management Agency).

\section{References}

[1] L. A. Weinstein, J. Loomis, B. Bhatia, D. M. Bierman, E. N. Wang, and G. Chen, "Concentrating Solar Power," Chem. Rev., vol. 115, no. 23, pp. 12797-12838, 2015.

[2] P. Parthasarathy and K. S. Narayanan, "Hydrogen production from steam gasification of biomass: Influence of process parameters on hydrogen yield - A review”, Renew. Energy, vol. 66, pp. 570-579, [3] N. Piatkowski and A. Steinfeld, "Solar-Driven Coal Gasification in a Thermally Irradiated PackedBed Reactor," Energy Fuels, vol. 22, pp. 2043-2052, 2008.

[4] Q. Bellouard, S. Abanades, S. Rodat, and N. Dupassieux, “A high temperature drop-tube and packed-bed solar reactor for continuous biomass gasification,” AIP Conf. Proc., vol. 1850, p. 100001, 2017.

[5] T. Abe, N. Gokon, T. Izawa, and T. Kodama, "Internally-circulating Fluidized Bed Reactor Using Thermal Storage Material for Solar Coal Coke Gasification,” Energy Procedia, vol. 69, pp. 1722-1730, 2015.

[6] S. Bellan, T. Kodama, K. Matsubara, N. Gokon, H. S. Cho, and K. Inoue, "performance of a $30 \mathrm{~kW}$ fluidized bed reactor for solar gasification: A CFD-DEM study,” Chem. Eng. J., vol. 360, pp. 1287-1300, 2018 
[7] F. Müller et al., "A pressurized high-flux solar reactor for the efficient thermochemical gasification of carbonaceous feedstock," Fuel, vol. 193, pp. 432-443, Apr. 2017.

[8] B. J. Hathaway, D. B. Kittelson, and J. H. Davidson, "Development of a Molten Salt Reactor for Solar Gasification of Biomass,” Energy Procedia, vol. 49, pp. 1950-1959, 2014.

[9] C. J. Noone, M. Torrilhon, and A. Mitsos, "Heliostat field optimization: A new computationally efficient model and biomimetic layout," Sol. Energy, vol. 86, no. 2, pp. 792-803, 2012.

[10] X. Li, Y. J. Dai, and R. Z. Wang, "Performance investigation on solar thermal conversion of a conical cavity receiver employing a beam-down solar tower concentrator," Sol. Energy, vol. 114, pp. 134$151,2015$.

[11] A. A. Kaniyal, P. J. van Eyk, G. J. Nathan, P. J. Ashman, and J. J. Pincus, "Polygeneration of Liquid Fuels and Electricity by the Atmospheric Pressure Hybrid Solar Gasification of Coal”, Energy Fuels, vol. 27, pp. 3538-3555, 2013.

[12] M. Sudiro and A. Bertucco, "Synthetic Fuels by a Limited CO2 Emission Process Which Uses Both Fossil and Solar Energy”, Energy Fuels, vol. 21, pp. 3668-3675, 2007.

[13] L. Salemme, M. Simeone, R. Chirone, P. Salatino, "Analysis of the energy efficiency of solar aided biomass gasification for pure hydrogen production”, Int. J. Hydrogen Energy, vol.39, pp. 14622-14632, 2014.

[14] X. Li, Y. Shen, X. Kan, T. K. Hardiman, Y. Dai, and C.-H. Wang, "Thermodynamic assessment of a solar/autothermal hybrid gasification CCHP system with an indirectly radiative reactor", Energy, vol. 142, pp. 201-214, 2018.

[15] J. Wang, C. Ma, and J. Wu, "Thermodynamic analysis of a combined cooling, heating and power system based on solar thermal biomass gasification”, Appl. Energy, vol. 247, pp. 102-115, 2019

[16] P. Guo, P. J. van Eyk, W. L. Saw, P. J. Ashman, G. J. Nathan, E. B. Stechell, "Performance assessment of Fischer-Tropsch liquid fuels production by solar hybridized dual fluidized bed gasification of lignite”, Energy \& Fuels vol. 29, pp.2738-2751, 2015.

[17] Z. Bai, Q. Liu, L. Gong, J. Lei, "Thermodynamic and economic analysis of a solar-biomass gasification system with the production of methanol and electricity", Energy Procedia, vol.152, pp.1045-1050, 2018. 
[18] W. L. Saw, P. Guo, P. J.van Eyk, G. J. Nathan, "Approaches to accommodate resource variability in the modelling of solar driven gasification processes for liquid fuels synthesis”, Solar Energy, vol.156, pp. 101112, 2017.

[19] «SciPy v1.3.0 Reference Guide ».

[20] S. Rodat, S. Abanades, G. Flamant, "Co-production of hydrogen and carbon black from solar thermal methane splitting in a tubular reactor prototype", Solar Energy, vol. 85, pp.645-652, 2011.

[21] W. L. Saw and S. S. Pang, "Influence of mean gas residence time in the bubbling fluidised bed on the performance of a 100-kW dual fluidised bed steam gasifier", Biomass Convers. Biorefinery, vol. 2, pp. 197-205, 2012

[22] N. J. Wagner, M. Coertzen, R. H. Matjie, and J. C. van Dyk, "Chapter 5 - Coal Gasification,” in Applied Coal Petrology, I. Suárez-Ruiz and J. C. Crelling, Eds. Burlington: Elsevier, 2008, pp. 119-144.

[23] J. Kitchin, « Gibbs energy minimization and the NIST webbook »,

[24] P. Charvin, S. Abanades, P. Neveu, F. Lemont, G. Flamant, "Dynamic modeling of a volumetric solar reactor for volatile metal oxide reduction", Chem. Eng. Research and Design. Vol. 86, pp. 1216-1222, 2008.

[25] S. Chuayboon, S. Abanades, and S. Rodat, "Experimental analysis of continuous steam gasification of wood biomass for syngas production in a high-temperature particle-fed solar reactor", Chem. Eng. Process. - Process Intensif., vol. 125, pp. 253-265, 2018.

[26] Q. Bellouard, S. Rodat, S. Abanades, S. Ravel, and P.-É. Frayssines, "Design, simulation and experimental study of a directly-irradiated solar chemical reactor for hydrogen and syngas production from continuous solar-driven wood biomass gasification", Int. J. Hydrog. Energy, vol. 44, pp. 19193-19205, 2019.

[27] H. Boujjat, S. Rodat, S. Chuayboon, and S. Abanades, "Numerical simulation of reactive gas-particle flow in a solar jet spouted bed reactor for continuous biomass gasification", Int. J. Heat Mass Transf., vol. 144, p. 118572, 2019.

[28] H. Boujjat, S. Rodat, S. Chuayboon, and S. Abanades, "Experimental and numerical study of a directly irradiated hybrid solar/combustion spouted bed reactor for continuous steam gasification of biomass", Energy, vol. 189, p. 116118, 2019. 
[29] J. C. Meerman, A. Ramírez, W. C. Turkenburg, and A. P. C. Faaij, "Performance of simulated flexible integrated gasification polygeneration facilities, Part B: Economic evaluation", Renew. Sustain. Energy Rev., vol. 16, no. 8, pp. 6083-6102, 2012. 